\title{
A 1,000-year ice core record of interannual to multidecadal variations in atmospheric circulation over the North Atlantic
}

Received: 1 May 2004 / Accepted: 31 January 2005

(C) Springer-Verlag 2005

\begin{abstract}
Interannual to multidecadal modes in ocean/ atmosphere dynamics in the North Atlantic region have been identified using sea salt aerosol proxy records from northern Greenland ice cores over the last 1,000 years. Sea salt concentrations show a consistent relationship with anomalies in the meridional pressure gradient over the North Atlantic region over all considered time scales. These pressure anomalies are connected to shifts in storm tracks, leading to lower pressure and higher storm activity, hence, higher sea salt export over the Greenland ice sheet. Two modes of long-term variability with a period of 10.4 years and 62 years could be identified. The latter is connected to long-term changes in sea surface temperature (SST) as documented by a high correlation of North Atlantic SST with our sea salt record over the last 150 years. Long-term reconstruction of these modes shows that the 10.4-year cycle has been a phenomenon persistent over the last millennium while the 62-year cycle has been mainly active after 1700 . Accordingly, the longer-term persistence of this multidecadal variability in sea salt points also to significant variations in SST over the last 300 years.
\end{abstract}

\section{Introduction}

Detailed knowledge about the occurrence and persistence of multiannual to multidecadal variations in atmospheric circulation and climate is a prerequisite to improve predictive skill in climate forecasting. This applies both to the forecasting of natural climate variations

H. Fischer $(\bowtie) \cdot$ B. Mieding

Alfred Wegener Institute for Polar and Marine Research,

Columbusstrasse, 27568 Bremerhaven, Germany

E-mail: hufischer@awi-bremerhaven.de

Tel.: +49-471-48311174

Fax: + 49-471-48311149 on interannual to multidecadal time scales as well as to the quantification and reliable prediction of a centennial anthropogenic climate change.

The interannual variability in atmospheric circulation over the North Atlantic is dominated by the pressure difference of the quasipermanent low over Iceland and the high over the Azores as reflected in the well-known North Atlantic Oscillation (NAO) (Hurrell et al. 2001; Wallace and Gutzler 1981). Empirical orthogonal function (EOF) analysis of spatially resolved annual pressure data for the North Atlantic region shows that more than one-third of the pressure variance in this region can be attributed to this dipole pattern (see Fig. 1a). The variation of this pressure gradient leads to significant changes in zonal circulation over the North Atlantic connected to pronounced changes in climate conditions on the eastern and western side of the North Atlantic (van Loon and Rogers 1978). Years in which the pressure gradient is larger than normal (positive NAO phases) are characterized by an enhanced westerly flow and, thus, warmer and wetter winters in Europe than for negative NAO years. At the same time positive NAO winters are characterized by lower precipitation in western Greenland (Appenzeller et al. 1998a) and enhanced sea ice coverage in the Baffin Bay. The second EOF (see Fig. 1b) in annual sea level pressure (SLP), explains close to $20 \%$ of the variance and is characterized by a monopole pattern located over the central North Atlantic $\left(55^{\circ} \mathrm{N}, 30^{\circ} \mathrm{W}\right)$.

Besides the mainly interannual climate variability connected to the NAO, significant variability in North Atlantic sea surface temperature (SST) and SLP has also been found on decadal to multidecadal time scales. For instance, a multidecadal variation in SST and SLP in the North Atlantic region (Delworth and Mann 2000; Deser and Blackmon 1993; Kushnir 1994; Schlesinger and Ramankutty 1994) with an apparent periodicity of 50 70 years is characterized by a cyclonic circulation anomaly centered around $45^{\circ} \mathrm{N}, 35^{\circ} \mathrm{W}$, which is connected to years of generally lower SST (Kushnir 1994). Tourre et al. (1999) also discuss quasidecadal variability 
in SST and SLP over the North Atlantic with a significant periodicity of 11.4 years, which is characterized by SLP anomalies in the central North Atlantic. Such longterm variability in atmospheric circulation comes about by atmosphere/ocean interactions. Accordingly, various coupled atmosphere/ocean model studies have tried to reproduce multidecadal modes in model runs and to identify possible coupling mechanisms (Delworth and Mann 2000; Griffies and Bryan 1997; Timmermann et al. 1998; Wu and Gordon 2002). While different explanations exist to show how long-term changes are communicated between atmosphere and ocean, all model studies agree that variations in the thermohaline circulation in the North Atlantic set the stage for multidecadal atmospheric circulation changes.

Unambiguously identifying such long-term circulation modes and deriving quantitative circulation indices on longer time scales, however, is hampered by the temporal coverage of spatially resolved instrumental data, which are limited to about 100-150 years (Basnett and Parker 1997; Kaplan et al. 1998, 2000). Using proxy data for climate and atmospheric circulation in the North Atlantic region derived from natural climate archives, the time scale for such studies can be considerably expanded and the persistence of multidecadal variations can be investigated. Because of the dominance of the NAO on the variance in SLP data over the North Atlantic several authors have attempted to reconstruct long-term variability in the NAO beyond the instrumental realm using tree rings, ice cores and combinations of climate indicators and instrumental data sets (Appenzeller et al. 1998b; Cook et al. 2002; Luterbacher et al. 1999, 2002). The results of these approaches differ considerably for the past centuries, probably due to nonstationarity of the NAO variability during the last 100 years, which usually is used as calibration period (Cook et al. 2002).

Here, we will present evidence of interannual to multidecadal variations in atmospheric pressure and cyclonic activity over the North Atlantic as deduced from sea salt aerosol concentrations in Northern Greenland ice cores. In contrast to many other proxy data (e.g. documenting proxy temperatures) the export of sea salt aerosol onto the Greenland ice sheet is directly related to storm activity and atmospheric circulation patterns (Fischer 2001). In addition, sea salt concentrations in Greenland ice show a seasonal maximum in the winter-half-year (Beer et al. 1991; Fischer and Wagenbach 1996; Steffensen 1988) and, accordingly, reflect mainly the atmospheric circulation during this time of the year, where its variance is greatest. In contrast to other proxy archives located at the western or eastern perimeter of the North Atlantic, which are strongly affected by changes in the westerlies, export of sea salt aerosol onto Greenland is dependent on variations in meridional transport and on overall north-south shifts of major storm tracks across the North Atlantic.

\section{Methods}

Ice cores for this study were drilled during the North Greenland Traverse (NGT) performed by the Alfred Wegener Institute during the years 1993-1995. Here, we present sea salt records from three ice cores: (B18: $76^{\circ} 37^{\prime} \mathrm{N} 36^{\circ} 24^{\prime} \mathrm{W} 2,508 \mathrm{~m}$ above sea level (a.s.l.), B20: $78^{\circ} 50^{\prime} \mathrm{N} 36^{\circ} 30^{\prime} \mathrm{W} 2,150 \mathrm{~m}$ a.s.1. B21: $80^{\circ} 00^{\prime} \mathrm{N} 41^{\circ} 08^{\prime} \mathrm{W}$ 2,136 $\mathrm{m}$ a.s.1.). The cores are located in the geographically and climatologically homogeneous northeastern outflow region of the Greenland ice sheet (see Fig. 2) characterized by consistently low snow accumulations (about $10 \mathrm{~cm}$ water equivalent per year) and average annual temperatures below $-30^{\circ} \mathrm{C}$. Sampling, decontamination, ion chromatographic analysis and dating of the cores B18 and B21 had been previously described in detail in Fischer (2001) and Fischer et al. (1998a, b). For core B20, identical sampling and analytical protocols have been used.

All cores have been subsampled in seasonal resolution (app. 4-10 samples per annual layer) over the time span 1959-1992, 1950-1993 and 1960-1993 for B18, B20 and $\mathrm{B} 21$, respectively, and stratigraphically dated for these intervals by counting annual cycles in multiproxy ion records with an accuracy better than 1 year (for an example of the stratigraphic dating using high-resolution ion chemistry records see e.g. Fig. 1 in Fischer (2001)).
Fig. 1 EOF analysis of annual mean SLP NCEP/NCAR reanalysis data for the North Atlantic region: a EOF1 explaining $39 \%$ and b EOF2 explaining $17 \%$ of the total variance, respectively

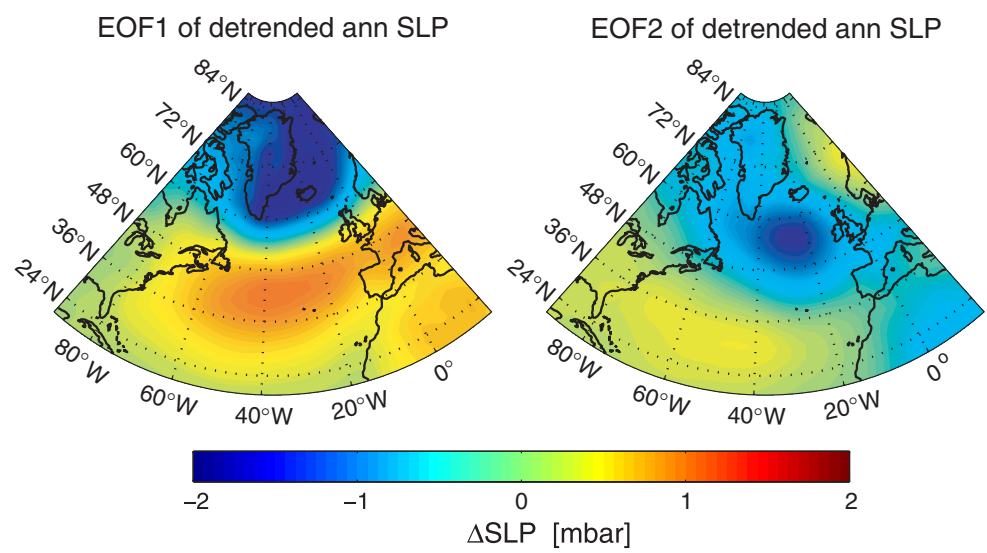


For older ages, coarse resolution samples (3-4 years/ sample for B18, 0.5-1 years/sample for B20 and 12 years/sample for B21) were taken covering up to the last 1,000 years. Dating of the NGT ice cores for these older ages was performed by identification of historic volcanic horizons in $\mathrm{SO}_{4}^{2-}$ (Fischer et al. 1998b) and high-resolution DC-conductivity profiles (Werner 1995) in combination with annual layer counting from highresolution $\gamma$-ray attenuation density measurements (Wilhelms, 1996) and high-resolution records in $\mathrm{Na}^{+}$, $\mathrm{Ca}^{2+}$ and $\mathrm{NH}_{4}^{+}$using continuous flow analysis (Bigler et al. 2002; Sommer 1996). The maximum dating error is less than \pm 5 years over the entire length of the cores and \pm 1 year for intervals close to volcanic time markers.

In the following part, $\mathrm{Na}^{+}$concentrations will be discussed in detail, which are almost exclusively of sea salt origin for Holocene conditions in Greenland (Fischer 2001). In the case of $\mathrm{Na}^{+}$the overall accuracy of the ion chromatographic measurements is $5-10 \%$ dependent on the concentration of the samples.

\section{Results and discussion}

Interannual variability

As depicted in Fig. 3, sea salt concentrations at the three sites show high interannual variability over the last 30 years. Specific years show higher or lower an-

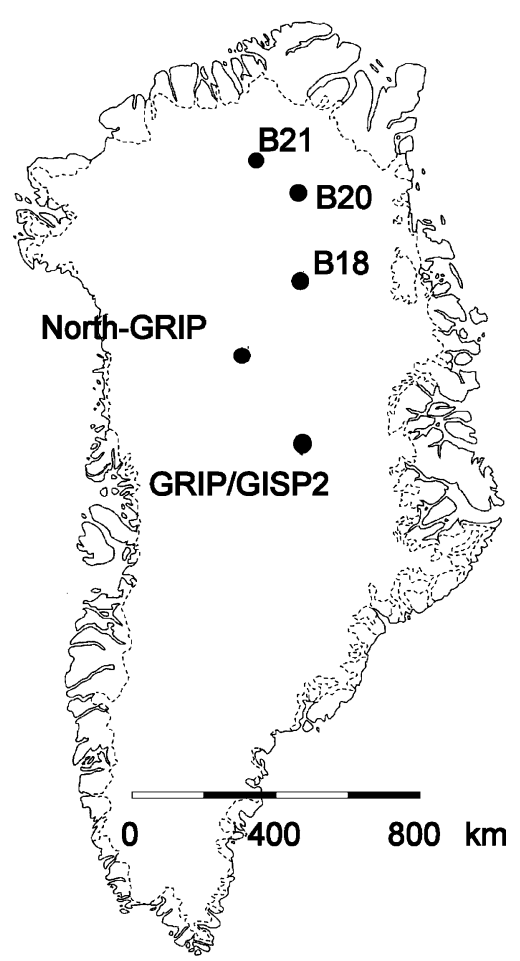

Fig. 2 Map of the Greenland ice sheet showing the three drill sites investigated in this study and selected deep drilling projects nual concentrations consistently in all three records. Interannual variability in ice core chemistry records is caused by changes in atmospheric aerosol concentrations but also by variability in the scavenging of atmospheric aerosol as well as by postdepositional changes in the snow pack. While the first of these factors is expected to cause coherent interannual variations for the three sites, which are located in the same geographic and meteorological regime on the ice sheet, the latter two lead to interannual variability differing from one site to the other. In the case of $\mathrm{Na}^{+}$, no postdepositional net loss is observed, however, wind drift may lead to limited reworking of snow strata. Studies on the spatial variability of ion concentrations in individual snowfall events performed at the Greenland Summit (Dibb and Jaffrezo 1997) showed that the spatial variability on a centimeter to kilometer scale is of the order of $30-40 \%$ for sodium. This is significantly less than the seasonal variation of about $500 \%$ found in our ice cores. Accordingly, the clear seasonal signal in our ice core records and the consistency of counted annual layers with prominent volcano horizons in the ice (Fischer 2001; Fischer et al. 1998b) imply that wind scouring may lead to intersite variability in snow concentrations; however, it is unlikely to remove complete annual layers. In the same studies on the Greenland Summit also the average annual $\mathrm{Na}^{+}$concentration of the snow pack sampled in specific years was shown to vary by about $30 \%$ on the centimeter to kilometer scale (Dibb and Jaffrezo 1997). This variation is only slightly lower than the temporal variability of mean annual concentrations in our individual ice cores (typically 40 $50 \%$ ). Accordingly, the signal-to-noise ratio in individual ice cores, especially in low accumulation areas, is rather low and interannual variability in single ice cores is hard to unambiguously detect. Spatially or temporally averaging ion concentrations in ice cores,

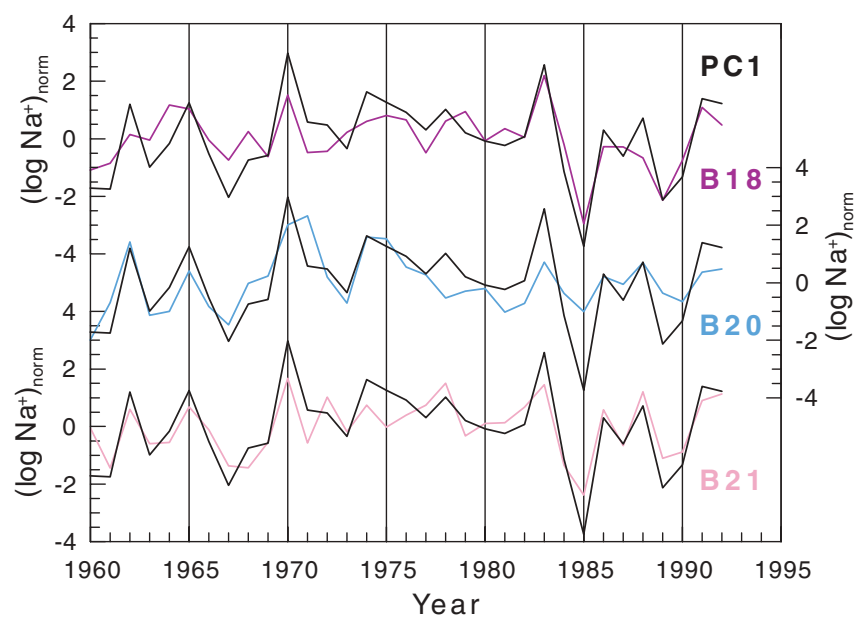

Fig. 3 Normalized logarithmic annual $\mathrm{Na}^{+}$concentrations for the cores B18 (purple line), B20 (blue line), B21 (pink line) and the first principal component (PC1) of all three records (black line) 
however, increases the signal-to-noise ratio considerably.

In order to separate intersite variability from the common information shared by all three records, we performed a principal component (PC) analysis on the annual sea salt records at the three sites over the time span 1960-1993, where high-resolution data was available for all three cores and where the dating error is constrained to better than \pm 1 year. To account for the lognormal distribution of the annual sea salt concentrations and the altitude-related changes in concentration averages between the sites, normalized logarithmic $\mathrm{Na}^{+}$concentrations were used. The first principal component (PC1 in Fig. 3) (which is nearly identical to a stack of the normalized logarithmic concentrations) explains $66 \%$ of the total variance in all three records. To identify circulation and storm track anomalies connected to years of high/low $\mathrm{Na}^{+}$concentration, we calculated anomaly maps of average annual SLP, geopotential height at the 500-mbar level (z500), where aerosol transport onto the Greenland ice sheet predominately occurs, and average annual storm activity at sea level and at the 500 mbar level using NCEP/ NCAR reanalysis data. The storm activity is represented by the annual average variance of bandpass-filtered (110 days) SLP and z500 data reflecting pressure variations connected to passing cyclones at a given grid point. Anomalies were calculated by picking years showing local maxima (1962, 1965, 1970, 1974, 1978, 1983, 1986, 1988, 1991) and local minima (1960, 1963, 1967, 1973, $1977,1981,1985,1987,1989)$ in PC1 and subtracting the average SLP fields for years with low $\mathrm{Na}^{+}$concentrations from the one with high $\mathrm{Na}^{+}$concentrations (Fig. 4).

The SLP anomaly plots in Fig. 4a, b clearly show two major features: a higher meridional pressure gradient over the North Atlantic - reminiscent of the NAO pattern-and clearly enhanced storm activity over Greenland, Iceland and the Labrador Sea in years of high sea salt concentrations compared to those with low sea salt concentrations. The z500 anomalies (Fig. 4c, d) show similar patterns, with the Icelandic low being not as
Fig. 4 Interannual pressure anomalies for years of high $\mathrm{Na}^{+}$concentrations minus those with low $\mathrm{Na}^{+}$ concentrations in $\mathrm{PC} 1$ in Fig. 3 for a annual mean SLP, b annual mean variance of bandpass (1-10 days)-filtered SLP indicating storm activity, $\mathbf{c}$ annual mean z500 and $\mathbf{d}$ annual mean variance of bandpass $(1-$ 10 days)-filtered z500
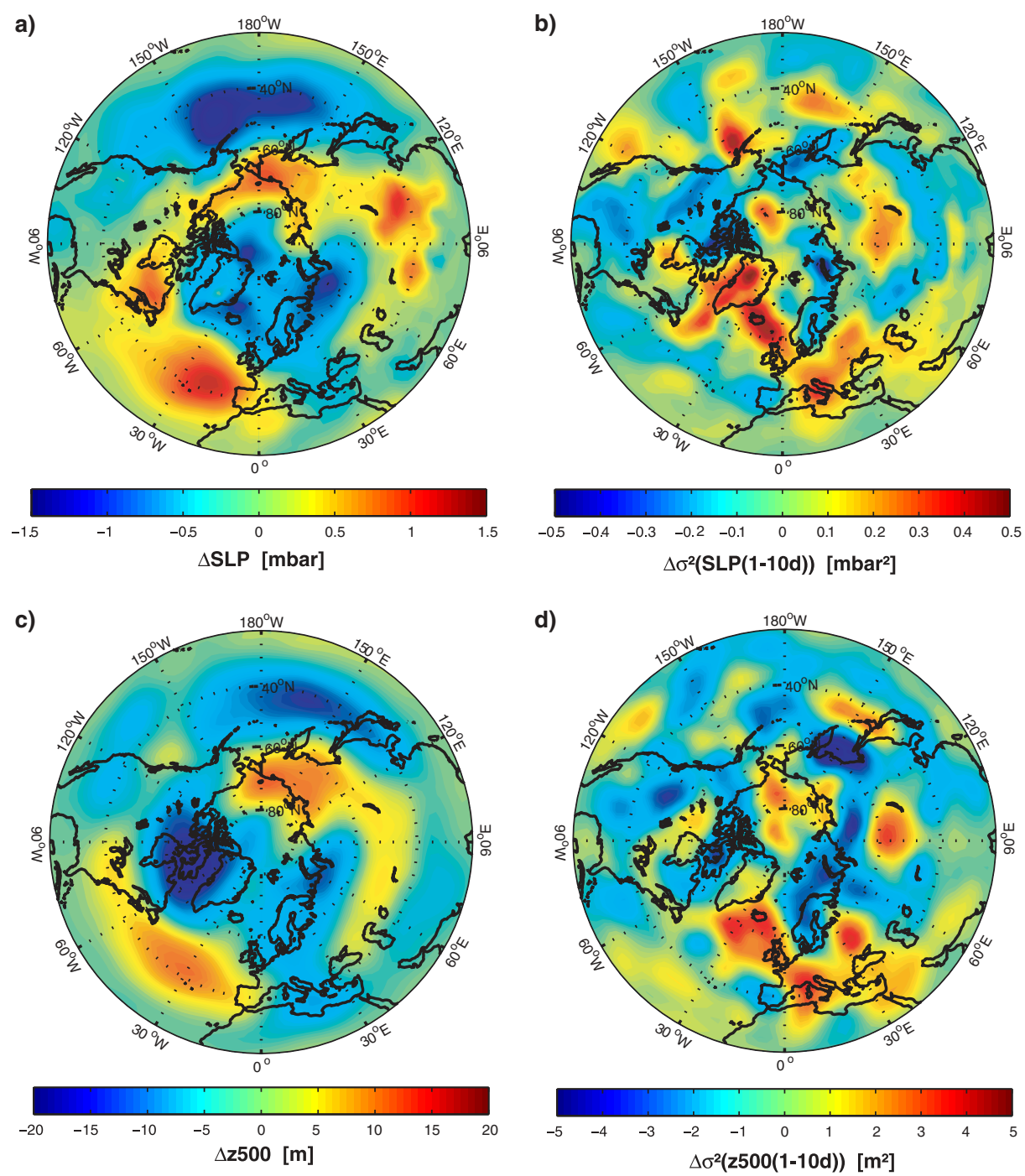
pronounced as in SLP for years of high $\mathrm{Na}^{+}$concentrations but being clearly the region of most enhanced storm activity. The same pattern is also found for geopotential height anomalies at the 700 mbar level (not shown), being representative for the altitude of the interior of the Greenland ice sheet.

Direct comparison of the NAO index with the sea salt records, however, leads to low correlation coefficients only. The main reason for this is the low signal-to-noise ratio in the ice core records and the non-linear relationship between meridional sea salt export and SLP via storm intensity and shifts in storm tracks in the North Atlantic region. Thus, the NAO index (pressure difference between Iceland and the Azores) is not necessarily a good measure for related sea salt export onto the Greenland ice sheet. An earlier spatial correlation analysis of sea salt with SLP and storm activity (Fischer 2001), using part of the ice core data presented here, revealed significant correlations not only in the North Atlantic region but also over the northern Pacific. Compared to the field correlation used in this earlier paper the anomaly patterns in the North Atlantic presented here are much more pronounced. This is because the anomaly method is robust against outliers and does not invoke a linear relationship between $\mathrm{Na}^{+}$and pressure data, which especially for storm activity cannot be a priori expected. In addition, the use of the common information archived in the three ice cores by the PC analysis instead of single ice core records improves the signal-to-noise ratio and allows for better identification of interannual variations in atmospheric aerosol concentrations. Based on this consistent relationship of sea salt export with pressure variability and related variations in storm tracks and storm activity over the North Atlantic, an apparent correlation of interannual variations in sea salt concentrations in Greenland with lower SLP in the northern Pacific reported earlier (Fischer 2001), seems not a robust long-term phenomenon but may be related to a current increase in SLP variability over the northern Pacific.

From the common information deduced from Fig. 4 we conclude that higher sea salt deposition onto the northeastern Greenland ice sheet is connected to the positive NAO phase leading to more frequent winter storms. In addition, storm tracks appear to cross the North Atlantic on a more northerly track. In contrast
Appenzeller et al. (1998a) derived lower precipitation rates in western Greenland and the Labrador sea connected to positive NAO phases, which would indicate reduced storm activity in this region. The latter is in line with the lower band pass filtered variance on the 500 mbar level in that region found in Fig. 4d. In contrast, eastern Greenland and the Greenland sea are regions of enhanced precipitation, hence, higher storm activity in their study, during years of predominately positive NAO. Accordingly, the results of Appenzeller et al. (1998a) and this study imply that the western and eastern Greenland outflow region, are responding in an opposite way to NAO circulation anomalies. In our case, the higher storm activity in the Iceland region leads to higher sea salt production and/or efficient export into the Greenland sea and eastern Greenland. At this point, we cannot quantify how much of the increase is due to higher sea salt aerosol production due to higher wind speeds within cyclonic systems and how much is due to more efficient transport of the preformed aerosol.

\section{Decadal and multidecadal variability}

The interpretation of interannual variability using ice core records on a longer time scale is hampered by potential dating errors and depositional noise as clearly reflected in the intersite variability. Accordingly, quantitative analysis of changes in aerosol concentrations in a single ice core record from one year to the other in terms of pressure anomalies is taking ice core interpretation to a limit. However, decadal to multidecadal variations in sea salt records are less affected by those problems because the dating error is substantially smaller than the time scale of these changes and the noise level is reduced due to the longer averaging time.

To quantify significant long-term changes over the last millennium, we performed Monte Carlo singular spectrum analysis (MC-SSA, maximum autocorrelation lag $M=180$ years) on the new annual $\mathrm{Na}^{+}$record from B20 covering the time period 1066-1993 with a stratigraphic dating error of better than \pm 5 years. The Monte Carlo significance test (Allen and Smith 1996) revealed six reconstructed components (RC) significantly different from red noise on the $95 \%$ significance level (Fig. 5a). RC1 reflects a long-term trend in $\mathrm{Na}^{+}$
Fig. 5 a MC-SSA analysis of core B20: $\mathrm{Na}^{+}$concentration (grey line), sum of RC2 to RC4 (purple line) and sum of RC5 and RC6 (orange line), b MCMESA analysis: spectrum of the $\mathrm{Na}^{+}$concentration in core B20 (black line) together with the Monte Carlo $99 \%$ significance level for red noise (red line), spectrum for the sum of RC1to RC4 (blue line) and for the sum of $\mathrm{RC} 1$ to $\mathrm{RC} 6$ (orange line)
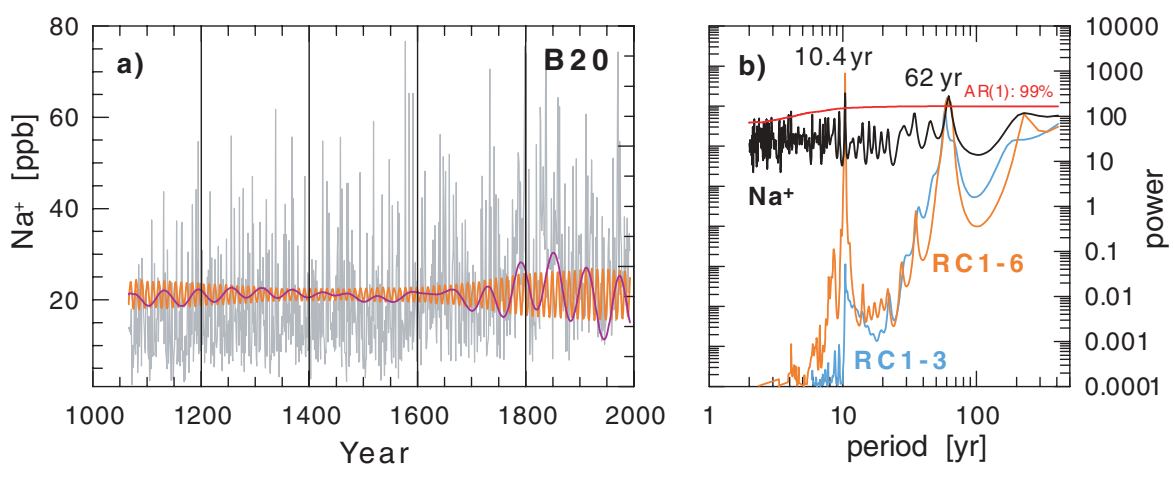
concentrations explaining $12 \%$ of the total variance and is characterized by a shift to higher concentrations at the end of the sixteenth century. In contrast RC2-RC6 are related to significant oscillatory modes as shown by the Monte Carlo maximum entropy power spectrum (MCMESA) in Fig. 5b. RC2-RC4 reflect multidecadal variability with a periodicity of 62 years in all three RCs, where RC2 is also affected by a long-term trend. Again, RC5-RC6 are characterized by a period of 10.4 years. These two long-term periodicities are also found to be significant, when performing MC-MESA on the complete $\mathrm{Na}^{+}$record of core B20 (black curve in Fig. 5b). The latter also shows significant variability on an interannual time scale. In view of the dating error, which is approximately of the same length as these interannual periodicities, we refrain from a quantitative interpretation of such high frequency variations in terms of pressure anomalies as performed for the last 30 years.

To reveal which long-term changes in atmospheric and oceanic conditions are responsible for the (multi)decadal changes in sea salt export onto the Greenland ice sheet, we performed an anomaly analysis similar to the one for the interannual variability. Years of extraordinarily high/low sodium concentrations were identified by picking years of local maxima and local minima in the RCs, i.e., where

$$
\sum \mathrm{RC}_{i}(t)>\text { ave }\left(\sum \mathrm{RC}_{i}\right)+\mathrm{SD}\left(\sum \mathrm{RC}_{i}\right)
$$

and

$\sum \mathrm{RC}_{i}(t)<\operatorname{ave}\left(\sum \mathrm{RC}_{i}\right)-\mathrm{SD}\left(\sum \mathrm{RC}_{i}\right)$

respectively (with ave representing the mean of the RC and SD its standard deviation. The index $i$ sums over $\mathrm{RC} 3$ and RC4 and RC5 and RC6 for the multidecadal and decadal mode, respectively). For those years, anomaly maps in annual average SLP over the time span 1871-1993 (Basnett and Parker 1997) and in annual average SST for the time span 1856-1993 (Kaplan et al. 1998) are plotted in Fig. 6. Unfortunately, no measure of storm activity is available for these extended time periods, because data frequency is not sufficient to calculate representative band pass filtered pressure data.
Fig. 6 Long-term anomalies in SLP (left) and SST (right) for periods of high $\mathrm{Na}^{+}$ concentrations minus those with low $\mathrm{Na}^{+}$concentrations in a, $\mathbf{b}$ the sum of $\mathrm{RC} 3$ and $\mathrm{RC} 4$ (multidecadal variation) and in c, $\mathbf{d}$ the sum of RC5 and RC6 (decadal variation)
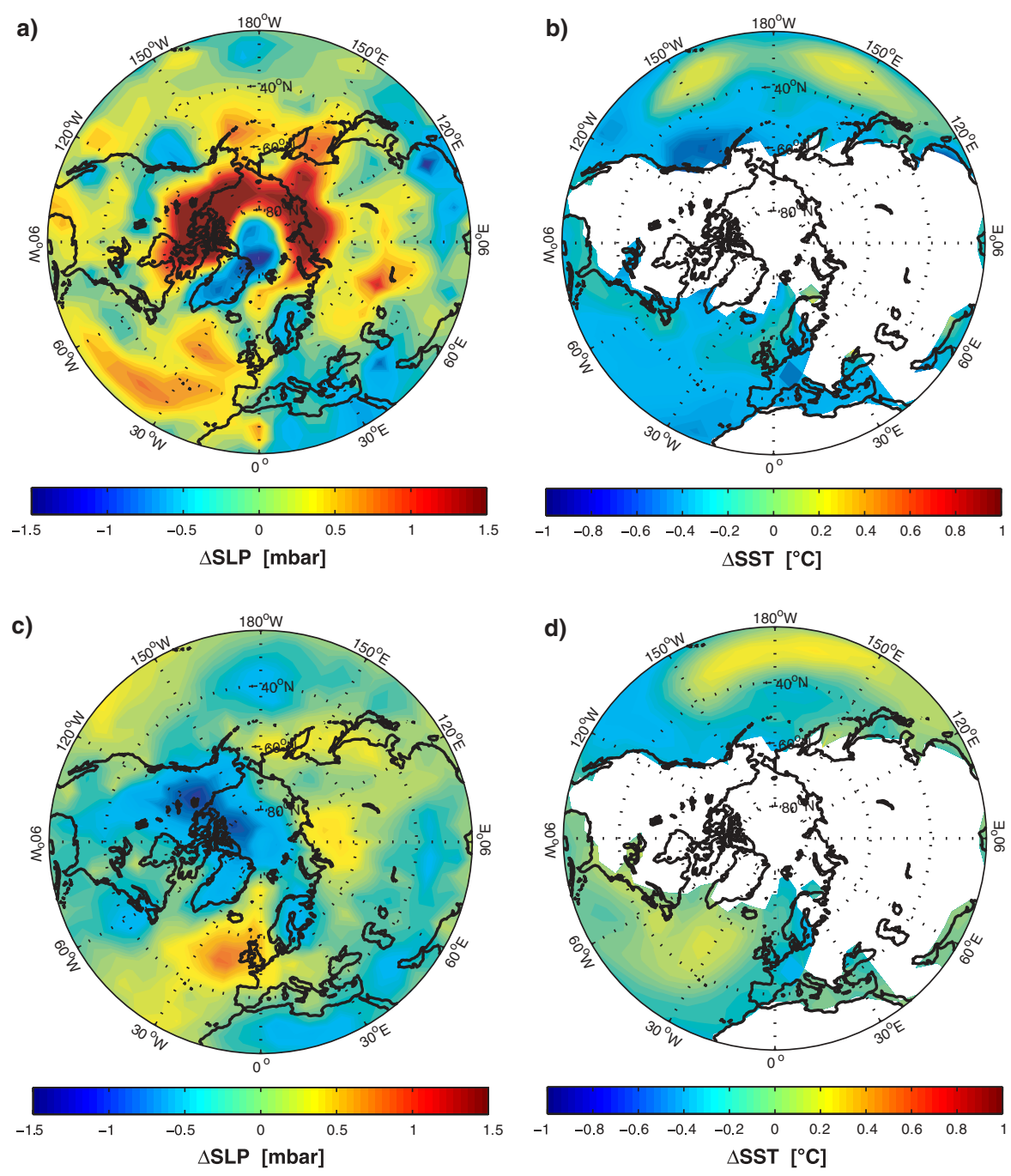
Accordingly, all conclusions on changes in storm activity are based on analogy with the interannual case discussed above.

For the multidecadal mode (Fig. 6a, b) the outcome of this analysis shows an overall negative anomaly in SST over the North Atlantic for intervals of higher sea salt concentration in northern Greenland compared to those with reduced sea salt concentration. The SLP anomaly pattern reveals higher pressures in the eastern Atlantic region and a clear deep pressure trough over Greenland. In analogy to the interannual variability, we suggest that the deeper pressure is connected to enhanced cyclonic activity entering the Greenland ice sheet, thus leading to enhanced sea salt export. Virtually the same anomaly patterns (not shown) are obtained using the common information inherent in the three cores B18, B20, B21 for the time period 1856-1993 by calculating the first PC (explaining $47 \%$ of the data variance) of normalized logarithmic triannual $\mathrm{Na}^{+}$records (see Fig. 7) and picking years where PC1 is higher/ lower than average. This clearly supports the regional representativeness of core $\mathrm{B} 20$ on multiannual to decadal time scales. Note, that this coherence on a multidecadal time scale also holds well for the rest of the core $\mathrm{B} 18$ and B20 and most of core B21 as illustrated in Fig. 8. The latter, however, shows a deviation from the common behavior of core $\mathrm{B} 20$ and $\mathrm{B} 18$ in the time interval 1770-1830. A potential dating error can be excluded due to the extremely good age constraint in this time interval defined by pronounced peaks in sulfate concentrations related to the Laki (1783) and Tambora (1815) eruption. Accordingly, this phase shift reflects true intersite variability, likely related to depositional noise. In view of the good correspondence of core B18 and $\mathrm{B} 20$, we tend to put more credibility into those two records in archiving the atmospheric changes in sea salt concentrations during that time interval.

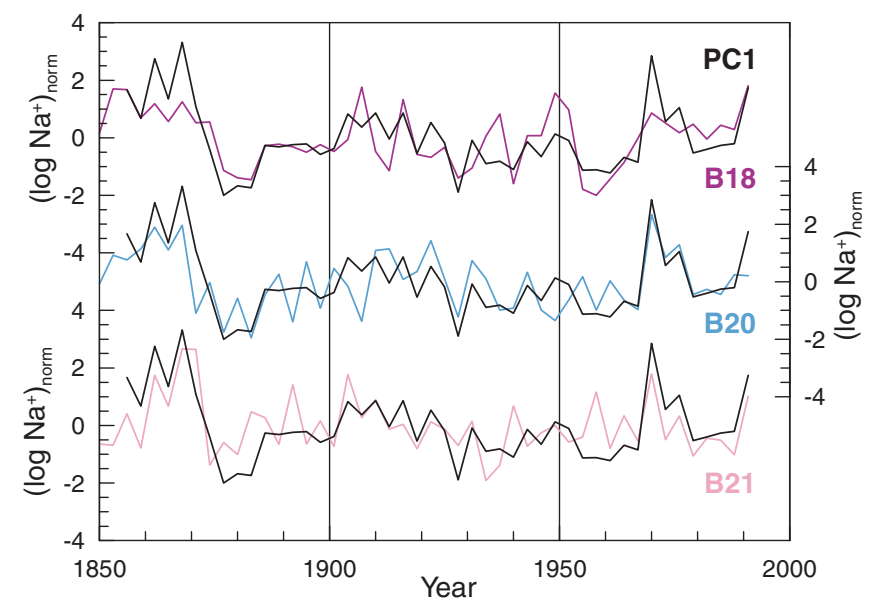

Fig. 7 Normalized logarithmic triannual $\mathrm{Na}^{+}$concentrations for the cores B18 (purple line), B20 (blue line), B21 (pink line) and the first principal component of all three records (black line) for the time interval 1856-1991
The SLP anomaly pattern for the multidecadal variation is only partly reminiscent of a NAO pattern. The general higher pressure in the eastern Atlantic can be related to the Azores high, however, a clear negative pressure anomaly over Iceland is absent and a high pressure anomaly appears also in the central North Atlantic. Nevertheless, the pressure distribution points to a northward shift of storm tracks over the Atlantic for periods of elevated sea salt concentrations. Because sea salt aerosol production is not causally connected to SST, the strong correlation of $\mathrm{PC} 1$ and SST is pointing to an indirect effect of SST on the storm activity and pressure distribution over the Northern Atlantic. Such a coupling has also been suggested by various model studies (Delworth and Mann 2000; Marshall et al. 2001; Wu and Rodwell 2004), where the long-term variability in SST itself has been attributed to variations in the thermohaline circulation.

A somewhat different picture emerges for the decadal variation in sea salt concentrations (Fig. 6c, d). Again, SLP shows a clear high-pressure anomaly in the central North Atlantic at $50^{\circ} \mathrm{N}$ and somewhat lower pressure over Greenland and especially the Canadian sector of the Arctic. In view of the results presented above a deflection of storm tracks into Greenland and the Arctic basin appears a possible explanation for this result. However, no clear anomaly can be found in North Atlantic SST and accordingly an oceanic influence on pressure patterns over the North Atlantic on this decadal time scale cannot be ascertained from this analysis. Since the time scale of this variation seems to be too long for an atmospheric process without ocean interaction other forcing factors such as solar insolation, showing a cycle of similar length, may be invoked to explain this feature. Another possible driving factor could be a teleconnection to changes in the Pacific region, e.g. related to the El Nino Southern Oscillation (ENSO) phenomenon. However, no clear SST or SLP anomalies emerge for the Pacific region. In addition, recent ENSO variability is largest on the multiannual time scale, while ENSO reconstructions only point to decadal variability for years prior to 1920 (Urban et al. 2000). In contrast, the 10.4 years cycle in our sodium record is most pronounced for the last century. Accordingly, the origin of the decadal mode remains obscure.

\section{Long-term persistence}

One of the key questions when addressing longer-term anomalies in atmospheric circulation is their persistence. Especially in the case of the multidecadal mode with a period of about 60 years (which is about half of the time span of the instrumental data) it may be questioned whether it represents really a cyclic phenomenon. Our sea salt record from core $\mathrm{B} 20$ can be used to expand the time span covered and to study the long-term persistence of the decadal and multidecadal mode. Note, that the fraction of total variance explained by the significant 


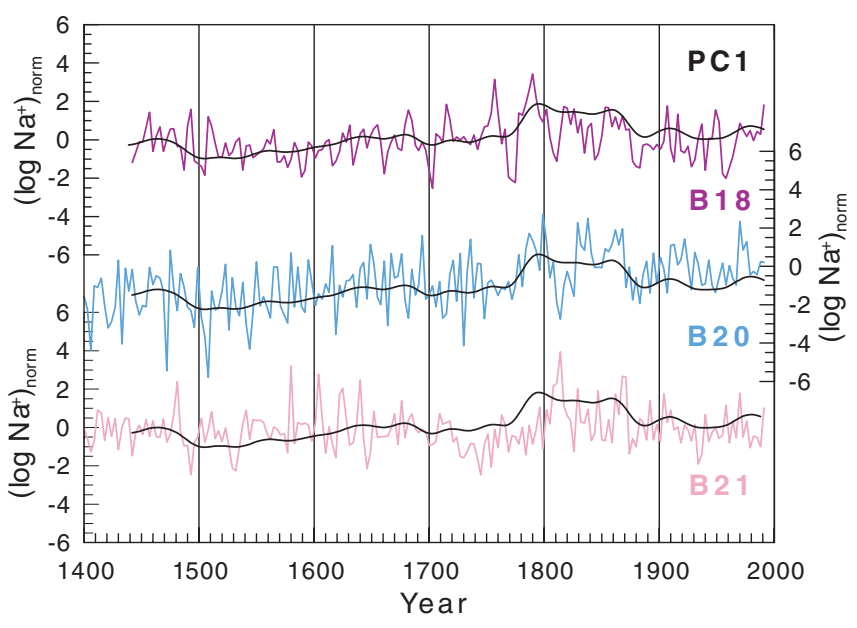

Fig. 8 Logarithmic triannual $\mathrm{Na}^{+}$records over the common time interval 1400 to present in the cores B18 (purple line), B20 (blue line), B21 (pink line) normalized to the time interval 1856-1991. The black line represents a Gaussian low pass (with a period of 50 years damped by $50 \%$ ) of the first principal component of the three records to illustrate the multidecadal coherence and deviations from it for the three records

eigenvectors in the MC-SSA analysis is rather low (about 6 and $3 \%$ for the 64 years and the 10.4 years cycle, respectively). This is due to the extremely high interannual variability in sodium concentrations related to true atmospheric variability and depositional noise. Accordingly, we refrain from a quantification of SLP and storm activity for individual years. However, an identification of cyclic (multi)decadal modes beyond the instrumental time span using our sea salt record in core B20 appears to be feasible.
In Fig. 9, the oscillatory MC-SSA components are plotted over the last 1,000 years together with other data documenting multi(decadal) climate variability over the last centuries. Clearly, the 62-year mode persists beyond the time span of instrumental data; however, it weakens considerably prior to 1700 . The lowest 62-year variability is found in the interval between 1400 and 1650 , a time period where generally colder temperature persisted in Europe as reflected in the socalled Little Ice Age (Grove 1990; Lamb (1979) and references therein). A similar picture holds for the 10.4year cycle, showing higher variability since 1700 and lowest variabilities between 1400-1650. However, an evolutionary power spectral analysis (not shown) identifies the 10.4-year cycle as significant throughout the record, while the 62-year cycle is only significantly different from red noise on the $95 \%$ level over the last 300 years.

In summary, both the multidecadal as well as the decadal mode appear to be significant longer-term phenomena of atmospheric dynamics over the North Atlantic region. Especially, the 10.4-year cycle shows persistence throughout the record, while the 62-year cycle is a feature prevalent over the last 300 years. Similar variability has also been documented e.g. in a foraminiferal record (number of Globigerina bulloides per gram of sediment) reflecting trade wind-induced upwelling in the Cariaco Basin (Black et al. 1999) as shown in Fig. 9. The last 100 years of the Cariaco Basin record have been dated using a well-constrained ${ }^{210} \mathrm{~Pb}$ and varve chronology of a nearby box core (Black et al. 1999) and its pronounced multidecadal variations are in excellent agreement with our stratigraphically dated ice core record at B20, showing in phase variability with the
Fig. 9 Comparison of the multidecadal variations in the $\mathrm{Na}^{+}$record of B20 with variations in SST in the Central Atlantic (Kushnir 1994), upwelling in the Cariaco Basin as indicated by the number concentration of the planctonic foraminifera Globigerina bulloides (Black et al. 1999) and the fifth reconstructed component (RPC 5) in a multiproxy network compiled by Mann et al. (1998) representing global multidecadal temperature variations

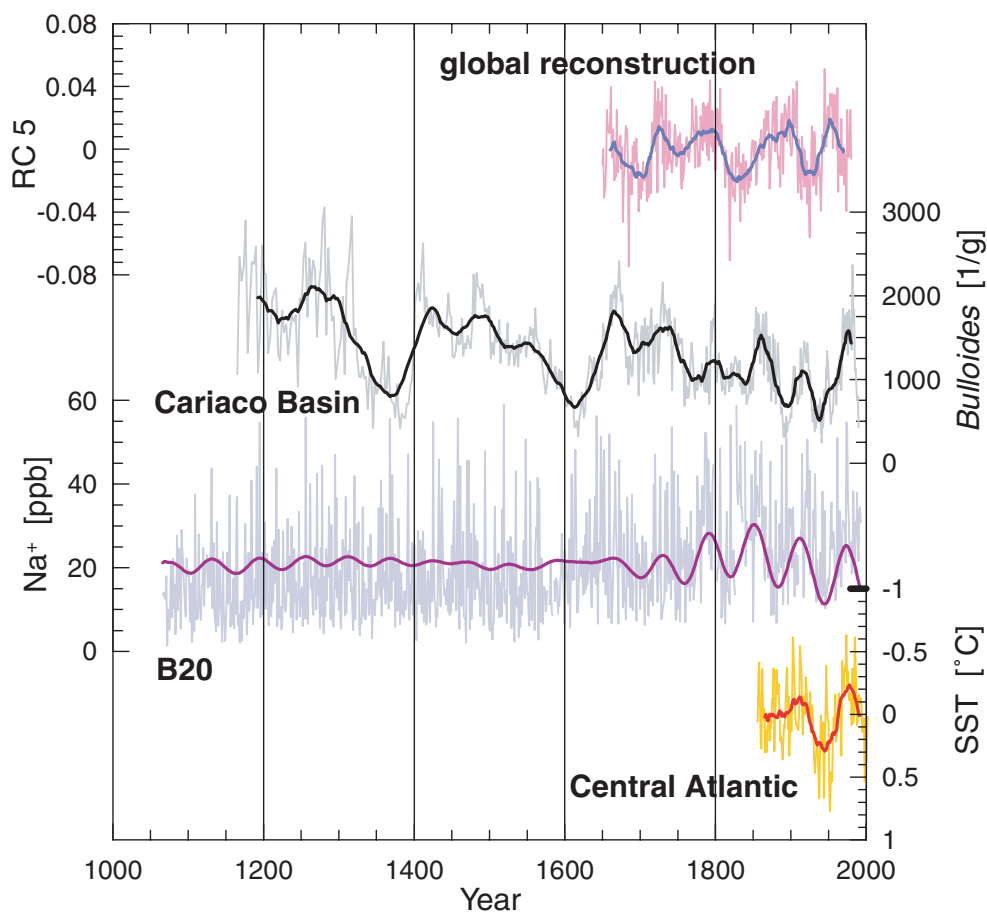


same period found in our sea salt record. For the time span 1900-1700 also, a comparable periodicity is found in the Cariaco Basin, however, with a phase shift of up to 20 years relative to our sea salt record. This phase shift is still within the dating accuracy of the Cariaco Basin record using ${ }^{14} \mathrm{C}$ ages for most of its 800 years. Prior to 1700 the coherence is weak. While B20 shows only weak signs of the multidecadal mode, the Cariaco Basin record still shows some multidecadal variability superimposed on sawtooth-shaped variations. The latter are not reflected in the ice core record at B20, pointing to a feature restricted to the tropical Atlantic leading to decreased upwelling, but having no significant effect on the North Atlantic climate. Comparison with the global climate reconstruction by Mann et al. (1998) using PC analysis on a global multiproxy network shows no correlation with our sea salt record. Only RPC5 in Mann et al. (1998) is characterized by multidecadal variability (see Fig. 9) which, however, has a longer period than the 62 -year mode in our sea salt record. We conclude, that the 62-year mode is a feature most prevalent in the North Atlantic region. Since the reconstruction by Mann et al. (1998) uses global data, it is likely to underestimate the importance of this variation for the North Atlantic region.

\section{Conclusions}

Using annual sea salt records from ice cores located in the northeastern outflow region of the Greenland ice sheet, we were able to identify temporal variations in large-scale pressure patterns and storm activity over the North Atlantic region. Most strikingly, both interannual as well as multidecadal variations in sea salt concentrations are consistently linked to the pressure gradient and changes in storm tracks over the North Atlantic and are connected to lower pressure and higher cyclonic activity in Greenland.

While the pressure patterns leading to higher sea salt concentrations in northeast Greenland resemble to some extent the NAO, the correlation between the instrumental NAO index (Hurrell 1995) and our sea salt record is low. The reason for this is, that the variance in the NAO index is dominated by inter- and multiannual variations, which cannot be quantitatively reconstructed from a single ice core record, due the low signal-to-noise ratio. In contrast, a high covariation exists between our sea salt record and a central North Atlantic SST index (Kushnir 1994) on a multidecadal time scale (Fig. 9). The main reason is probably the longer integration time of the ocean, thus, the low interannual variability of SST leading to a long-term tendency of the atmosphere to stay in one preferred mode, which is reliably archived in the ice core record.

A series of studies on data and coupled climate models (Delworth and Mann 2000; Marshall et al. 2001; Rodwell et al. 1999; Wu and Rodwell 2004) points to variations in deep-water formation in the North Atlantic (as e.g. during the great salinity anomaly in the 1970s (Delworth et al. 1997; Dickson et al. 1988)) being responsible for multidecadal SST variations. Based on our 1,000-year sea salt record, which is related to long-term SST variations, we may speculate that variations in the Atlantic meridional overturning could have occurred throughout the last 300 years, but were weaker prior to 1700 . Accordingly, new long-term ice core records from northern Greenland such as the currently completed North-GRIP deep ice core (North Greenland Ice Core Project members 2004) promise sensitive data on the atmospheric response on multidecadal variations in SST and potentially deep-water formation in the North Atlantic for the Holocene period.

In the glacial time rapid climate variations (Dansgaard Oeschger (DO) events) prevailed in the North Atlantic region as documented in Greenland ice core records (Johnsen et al. 1992). The DO events are also clearly imprinted in Northern Atlantic sediments (Bond et al. 1993) accompanied by a SST decrease of $3-6^{\circ} \mathrm{C}$ (McManus et al. 1999). These variations were also connected to substantial changes in the aerosol load over Greenland, with sea salt concentration being more than a factor of five higher in stadials than in interstadials (Mayewski et al. 1994). Based on our anomaly analysis, which showed a doubling of multidecadal $\mathrm{Na}^{+}$concentrations in northern Greenland connected to SST variations of approximately $0.5^{\circ} \mathrm{C}$ over the last 150 years, the sea salt increase during the DO events would only require a surface cooling of about $2^{\circ} \mathrm{C}$, which is at the lower end of values observed in the sediment records. Of course this analogy is speculative and holds only if our late Holocene relationship between sea salt and SST can also be extrapolated to glacial conditions, where, however, sea ice coverage and storm tracks had considerably changed. Clearly, the relationship of sea salt aerosol production and export onto the Greenland ice sheet today but especially during glacial conditions deserves further research based on ice cores, marine sediments as well as ocean/atmosphere circulation models.

Acknowledgments This is a contribution to the research strategy project "Natural climate variations from 10,000 to the present" (KIHZ) by the Helmholtz association of German research centers, funded by the German Ministry for Education and Research and in part of the EU project "Patterns of Climate Variability in the North Atlantic" (PACLIVA). We especially thank G. Lohmann for fruitful discussions and comments on this work and the PACLIVA ice core team on helpful comments. NCEP reanalysis data were kindly provided by the NOAA-CIRES Climate Diagnostics Center, Boulder, Colorado, USA (at http:// www.cdc.noaa.gov/).

\section{References}

Allen MR, Smith LA (1996) Monte Carlo SSA: detecting irregular oscillations in the presence of colored noise. J Clim 9:3373-3404 
Appenzeller C, Schwander J, Sommer S, Stocker TF (1998a) The North Atlantic Oscillation and its imprint on precipitation and ice accumulation in Greenland. Geophys Res Lett 25:19391942

Appenzeller C, Stocker TF, Anklin M (1998b) North Atlantic Oscillation dynamics recorded in Greenland ice cores. Science 282:446-449

Basnett TA, Parker DE (1997) Development of the global mean sea level pressure data set GMSLP2. Hadley Center Climate Research Technical Note CRTN 79

Beer J, Finkel RC, Bonani G, Gäggeler H, Glach U, Jacob P, Klockow D, Langway CCJ, Neftel A, Oeschger H, Schotterer U, Schwander J, Siegenthaler U, Suter M, Wagenbach D, Wölfli W (1991) Seasonal variations in the concentrations of ${ }^{10} \mathrm{Be}, \mathrm{Cl}^{-}, \mathrm{NO}_{3}^{-}, \mathrm{SO}_{4}^{2-}, \mathrm{H}_{2} \mathrm{O}_{2},{ }^{210} \mathrm{~Pb},{ }^{3} \mathrm{H}$, mineral dust, and $\delta^{18} \mathrm{O}$ in Greenland snow. Atmos Environ 25:899-904

Bigler M, Sommer S, Stauffer B, Wagenbach D, Fischer H, Kipfstuhl J, Miller H (2002) Sulphate record from a northeast Greenland ice core over the last 1200 years based on continuous flow analysis. Ann Glac 35:250-256

Black DE, Peterson LC, Overpeck JT, Kaplan A, Evans MN, Kashgaraian M (1999) Eight centuries of North Atlantic ocean atmosphere variability. Science 286:1709-1713

Bond G, Broecker W, Johnsen S, McManus J, Labeyrie L, Jouzel J, Bonani G (1993) Correlations between records from North Atlantic sediments and Greenland ice. Nature 365:143-147

Cook ER, D'Arrigo RD, Mann ME (2002) A well-verified, multiproxy reconstruction of the winter North Atlantic Oscillation index since A.D. 1400. J Clim 15:1754-1764

Delworth TL, Mann ME (2000) Observed and simulated multidecadal variability in the Northern Hemisphere. Clim Dyn 16:661-676

Delworth TL, Manabe S, Stouffer RJ (1997) Multidecadal climate variability in the Greenland Sea and surrounding regions: a coupled model simulation. Geophys Res Lett 24:257-260

Deser C, Blackmon ML (1993) Surface climate variations over the North Atlantic ocean during winter: 1900-1989. J Clim 6:17431753

Dibb JE, Jaffrezo JL (1997) Air-snow exchange investigations at Summit, Greenland: an overview. J Geophys Res 102:2679526808

Dickson RR, Meinke J, Malmberg SA, Lee AJ (1988) The "Great Salinity Anomaly" in the northern North Atlantic 1968-82. Prog Oceanogr 20:103-151

Fischer H (2001) The imprint of large-scale atmospheric transport patterns on sea salt records in Northern Greenland ice cores. J Geophys Res 106:23977-23984

Fischer H, Wagenbach D (1996) Large-scale spatial trends in recent firn chemistry along an east-west transect through central Greenland. Atmos Environ 30:3227-3238

Fischer H, Wagenbach D, Kipfstuhl J (1998a) Sulfate and nitrate firn concentrations on the Greenland ice sheet 1. Large-scale geographical deposition changes. J Geophys Res 103:2192721934

Fischer H, Wagenbach D, Kipfstuhl J (1998b) Sulfate and nitrate firn concentrations on the Greenland ice sheet 2. Temporal anthropogenic deposition changes. J Geophys Res 103:2193521942

Griffies SM, Bryan K (1997) Predictability of North Atlantic multidecadal climate variability. Science 275:181-184

Hurrell JW (1995) Decadal trends in the North Atlantic Oscillation: regional temperatures and precipitation. Science 269:676679

Hurrell JW, Kushnir Y, Visbeck M (2001) The North Atlantic Oscillation. Science 291:603-605

Johnsen SJ, Clausen HB, Dansgaard W, Fuhrer K, Gundestrup N, Hammer CU, Iversen P, Jouzel J, Stauffer B, Steffensen JP (1992) Irregular glacial interstadials recorded in a new Greenland ice core. Nature 359:311-313

Kaplan A, Cane M, Kushnir Y, Clement A, Blumenthal M, Tajagopalan B (1998) Analyses of global sea surface temperature 1956-1991. J Geophys Res 103:18567-18589
Kaplan A, Kushnir Y, Cane MA (2000) Reduced space interpolation of historical marine sea level pressure: 1954-1992. J Clim 13:2987-3002

Kushnir Y (1994) Interdecadal variations in North Atlantic sea surface temperature and associated atmospheric conditions. J Clim 7:141-157

Lamb HH (1979) Climatic variation and changes in the wind and ocean circulation: the Little Ice Age in the northeast Atlantic. Q Res 11:1-20

van Loon H, Rogers JC (1978) The seesaw in winter temperatures between Greenland and northern Europe: part I: general description. Mon Weather Rev 106:296-310

Luterbacher J, Schmutz C, Gyalistras D, Xoplaki E, Wanner H (1999) Reconstruction of monthly NAO and EU indices back to AD 1675. Geophys Res Lett 26:2745-2748

Luterbacher J, Xoplaki E, Dietrich D, Jones PD, Davies TD, Portis D, Gonzalez-Rouco JF, von Storch H, Gyalistras D, Casty C, Wanner H (2002) Extending North Atlantic Oscillation reconstructions back to 1500. Atmos Sci Lett DOI 10.1006/ asle. 2001.0044

Mann ME, Bradley RS, Hughes MK (1998) Global-scale temperature patterns and climate forcing over the past six centuries. Nature 392:779-787

Marshall J, Johnson H, Goodman J (2001) A study of the interaction of the North Atlantic Oscillation with ocean circulation. J Clim 14:1399-1421

Mayewski PA, Meeker LD, Whitlow S, Twickler MS, Morrison MC, Bloomfield P, Bond GC, Alley RB, Gow AJ, Grootes PM, Meese DA, Ram M, Taylor KC, Wumkes W (1994) Changes in atmospheric circulation and ocean ice cover over the North Atlantic during the last 41000 years. Science 263:1747-1751

McManus JF, Oppo DW, Cullen JL (1999) A 0.5-million-year record of millenial climate variability in the North Atlantic. Science 283:971-975

North Greenland Ice Core Project members (2004) High resolution climate record of the northern hemisphere reaching into the last interglacial period. Nature 431:147-151

Rodwell MJ, Powell DP, Folland CK (1999) Oceanic forcing of the wintertime North Atlantic Oscillation and European climate. Nature 398:320-323

Schlesinger ME, Ramankutty N (1994) An oscillation in the global climate system of period 65-70 years. Nature 367:723-726

Sommer S (1996) Hochauflösende Spurenstoffuntersuchungen an Eisbohrkernen aus Nord-Grönland. Master thesis Physikalisches Institut, Universität Bern

Steffensen JP (1988) Analysis of the seasonal variation in dust, $\mathrm{Cl}^{-}$, $\mathrm{NO}_{3}^{-}$, and $\mathrm{SO}_{4}^{2-}$ in two central Greenland firn cores. Ann Glac 10:171-177

Timmermann A, Latif M, Voss R, Grötzner A (1998) Northern hemispheric interdecadal variability: a coupled air-sea mode. J Clim 11:1906-1931

Tourre YM, Rajagopalan B, Kushnir Y (1999) Dominant patterns of climate variability in the Atlantic Ocean during the last 136 years. J Clim 12:2285-2299

Urban FE, Cole JE, Overpeck JT (2000) Influence of mean climate change on climate variability from a 155 -year tropical Pacific coral record. Nature 407:989-993

Wallace JM, Gutzler DS (1981) Teleconnections in the geopotential height field during the northern hemisphere winter. Mon Weather Rev 109:784-812

Werner M (1995) Vergleichende Studie über die Verteilung vulkanogener Spurenstoffdepositionen in Nord-Ost-Grönland. Master thesis Institut für Umweltphysik, Universität Heidelberg

Wilhelms F (1996) Measuring the conductivity and density of ice cores. Ber Polarforsch 191:1-224

Wu P, Gordon C (2002) Oceanic influence on North Atlantic climate variability. J Clim 15:1911-1925

Wu P and Rodwell MJ (2004) Gulf Stream forcing of the winter North Atlantic Oscillation. Atmos Sci Lett 5:57-64 